\title{
Drug Shortages: What Can Hospital Pharmacists Do?
}

\author{
Régis Vaillancourt
}

$\mathrm{H}$ ospital pharmacists have become accustomed to drug shortages over the past few years. For example, in 2010, 94\% of Canadian pharmacists surveyed claimed that they had had difficulty locating a medication during the previous week. ${ }^{1}$ A 2010 survey of members of the American Society of HealthSystem Pharmacists indicated that both pharmacists and pharmacy technicians were spending an average of 8-9 h/week dealing with issues related to drug shortages. ${ }^{2}$ Furthermore, drug shortages are not limited to North America, but rather are a worldwide problem. ${ }^{3}$ The causes of drug shortages are multifactorial and include supply disruptions, changes to regulatory requirements, shortages of raw materials, recalls, government pricing strategies, and monopolization of manufacturing. ${ }^{1}$ With the current shortages of Sandoz products (first announced in February 2012), hospital pharmacy managers spend most of their days monitoring the drug supply and working with clinicians to deal with the shortages. The question considered here is, What can hospital pharmacists do to prevent further exacerbation of the human-caused crisis we are currently facing?

In this era of globalization, drug manufacturers, like hospitals, are always seeking to save money. One way to reduce costs is the concentration of manufacturing. However, if production within a particular company slows down, the whole world may be affected. In a recent study published by the US Food and Drug Administration, 55 (43\%) of 127 shortages were attributed to manufacturing quality problems. ${ }^{4}$ Does this sound familiar?

What role did hospital pharmacists play in the development of the current situation? Hospitals are mandated to provide high-quality care while saving money. As pharmacy managers, many of us deal with a group purchasing organization, such as SigmaSanté in Québec and Medbuy or HealthPRO in the rest of Canada. These 3 buying groups represent about $90 \%$ of the Canadian hospital pharmacy market. So what is the connection between group purchasing and the current drug shortages? It arises from the concept of "winner take all". ${ }^{3}$

Currently, group purchasing organizations put out requests for proposals (RPFs) for a 3- to 5-year term, which allows the single supplier chosen to reduce its production costs and submit a lower bid on the next RFP. As an example, assume there are 3 manufacturers of a specific injectable product, drug X. Bids submitted in response to an RFP are assessed, and the contract is given to the lowest bidder, supplier Y. When the next RFP is put forward, supplier Y already has a secure production

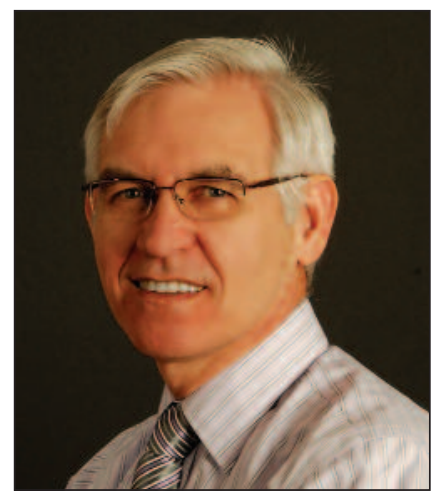

line for drug $X$, which allows it to bid at a lower price than the other 2 suppliers. Over time, supplier Y may get contracts with all 3 major group purchasing organizations. At that point, it may no longer be cost-effective for other suppliers to keep producing drug $\mathrm{X}$, because their production costs will be too high, and they will probably stop producing drug X. In this way, trying to save money on hospital drug budgets leads to decreased competition and a situation in which supplier $Y$ is the only manufacturer of drug X. If this supplier's plant goes "down" for some reason, we are in trouble. In fact, this is what is happening right now!

What can we learn from the current drug shortages? The simple answer is that we need to maintain healthy competition in the Canadian drug market to secure the chain of supply of essential drugs. This is not a new concept. For example, the federal, provincial, and territorial vaccine contracting group understood the risk years ago. This contracting group is responsible for nationwide procurement of vaccines. To maintain Canadian manufacturing capacity for the influenza vaccine, the group has been awarding a split contract for many years, giving the majority of the business to the lowest bidder and the remainder to the second- and possibly third-lowest bidders. The split may be $50 \%-25 \%-25 \%$ if there are 3 suppliers or $70 \%-30 \%$ if there are only 2 . This approach ensures that more than one manufacturer is able to maintain a production chain. In contrast, New Zealand had a single-source provider for influenza vaccine 
(Sanofi-Pasteur). In 2005, it was discovered that one of the influenza strains was underdosed in the vaccine, which meant the government had to scramble for another supplier just before flu season. If split contracts had been awarded, the problem and associated consequences of losing the vaccine supply might have been avoided.

The practice of splitting contracts is not common, but some group purchasing organizations are now looking into this possibility. For example, the Medbuy Pharmacy Committee has identified 20 essential injectable drugs for which there are only 2 or 3 suppliers in Canada. Of these, 5 have been selected for split contracts. This approach requires the collaboration of both suppliers and hospitals. The suppliers must be willing to provide a competitive bid even if they do not get $100 \%$ of the business, and hospitals must be willing to pay more for part of the contract. Even if we are trying to cut costs, we must support an environment that maintains healthy competition, and split contracts are one way to accomplish this goal.

Back in 2008, the government of Canada was made aware of the risk of a lack of drug supply for the Canadian population and the danger of shrinking competition among generic drug manufacturers. ${ }^{6}$ With the current crisis in the public eye, now is the perfect opportunity to ensure that the government is made aware of steps that can be taken to improve the medication supply.

So, while we await a more global solution to drug shortages, we need to convince our hospital administrators and the government to consider innovative procurement methods that will maintain healthy competition in the drug market and allow us to take care of our patients.

\section{References}

1. Canadian drug shortages survey: final report. Ottawa (ON): Canadian Pharmacists Association; 2010 [cited 2012 Mar 27]. Available from: www.pharmacists.ca/cpha-ca/assets/File/cpha-on-the-issues/DrugShortage Report.pdf

2. Kaakeh R, Sweet BV, Reilly C, Bush C, DeLoach S, Higgins B, et al. Impact of drug shortages on U.S. health systems. Am J Health Syst Pharm 2011; 68(19):1811-1819.

3. Gray A, Manasse HR Jr. Shortages of medicines: a complex global challenge. Bull World Health Organ 2012;90(3):158-158A.

4. A review of FDA's approach to medical product shortages. Silver Spring (MD): US Food and Drug Administration; 2011 [cited 2012 May 23]. Available from: www.fda.gov/downloads/aboutfda/reportsmanualsforms/reports/ ucm277755.pdf

5. MacKay P. Is PHARMAC's sole supply tendering policy harming the health of New Zealanders? J $N$ Med Assoc 2005 [cited 2012 Mar 28]; 118(1214):U1433. Available from: http://journal.nzma.org.nz/journal/ $118-1214 / 1433 /$

5. Benefiting from generic drug competition in Canada: the way forward. Ottawa (ON): Competition Bureau of Canada; 2008 Nov [cited 2012 May 25]. Available from: www.competitionbureau.gc.ca/eic/site/cb-bc.nsf/vwapj/ GenDrugStudy-Report-081125-fin-e.pdf/\$FILE/GenDrugStudy-Report081125-fin-e.pdf

Régis Vaillancourt, OMM, CD, BPharm, PharmD, FCSHP, is Director of Pharmacy with the Children's Hospital of Eastern Ontario, Ottawa, Ontario. He is also an Associate Editor with the CJHP.

\section{Address correspondence to:}

Dr Régis Vaillancourt

Children's Hospital of Eastern Ontario

401 Smyth Road

Ottawa ON K1H 8L1

e-mail: Rvaillancourt@cheo.on.ca

\section{ON THE FRONT COVER}

\section{A Dock in Quebec}

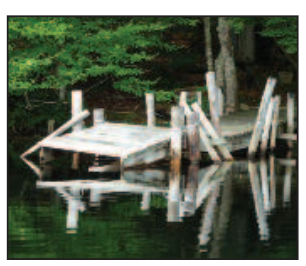

The cover photograph, taken in summer 2011, epitomizes a lazy and peaceful day at the cottage. The dilapidated dock, located on a small lake near Wakefield, Quebec, has been lovingly and painstakingly held together with anything on hand. The image was captured by Caroline Cheng, a hospital pharmacist working in Ottawa, using a Panasonic Lumix DMC-ZS5 camera.

The CJHP would be pleased to consider photographs featuring Canadian scenery taken by CSHP members for use on the front cover of the journal. If you would like to submit a photograph, please send an electronic copy (minimum resolution $300 \mathrm{dpi}$ ) to Colleen Drake at cdrake@cshp.ca. 